\title{
7 \\ Growing Up Fast in Two Remote Aboriginal Communities
}

\author{
Sue McMullen
}

In this chapter, I focus on how young Aboriginal women find sexual partners, often with a view to marriage and child-bearing, in two communities. The first is a remote Aboriginal community that is restricted: non-residents must obtain a permit to enter (hereafter 'the community'). I lived and worked as a nurse in the community for several years. The second is a town, in the sense that there is unrestricted movement of both Indigenous and non-Indigenous people, but it is still a remote community (hereafter 'the town'). It is situated on the edge of Arnhem Land and is close to major mining developments. As such, the town has regular contact with non-Indigenous workers. A steady stream of nonIndigenous tourists also visit, attracted by fishing opportunities in the area. In contrast to the community, alcohol is readily available in the town. I visited the town regularly over a period of three years while researching my $\mathrm{PhD}$ thesis. Both places are connected through country and kinship relationships with family members travelling from one community to the other for funerals, ceremonies and social visits. In both, young Indigenous women appear to be growing up fast and forming sexual relationships in the early years of adolescence.

Two bodies of evidence inform this chapter. The first is based on my experience as a nurse in the community, with responsibility (among many other things) for the sexual health of young people. During this period, my view of young people's sexual relationships was narrow, confined to health education initiatives and point of care at the clinic. In terms of 
the numbers of teenage pregnancies and sexually transmitted infections, I was able to observe the scope of the issue, but I was not in a position to understand the motivation of young women and the decisions they made regarding their relationships. In 2012, I began my PhD research in the town of Boroloola. During this time, I lived in the town and was able to observe the lives and interactions of young women, as well as how their actions were perceived by older members of the community. My participant observation was supplemented by in-depth interviews with women and workshops exploring sexual decision-making. Many of the young women were reluctant to talk to me; therefore, explanations for some of the behaviours I observed were obtained from older women, whose perspectives may have been influenced both by their concern for, and propensity to critique, the younger generation.

Early sexual experience can have significant effects on the sexual and reproductive health of young Indigenous women, including higher rates of underage pregnancy and sexually transmitted infections. Such women and their children often experience negative long-term outcomes (Stark and Hope 2007). Early sexual relationships can also influence developmental outcomes, as those who are sexually active can disengage from education. This is due to the late nights in which young people carve out their personal space and time away from the eyes of adults (Senior and Chenhall 2008). They may have minimal knowledge about life choices that are not linked to relationships and reproduction (McMullen 2015). Premature reproduction, generally, is associated with negative or less than optimal outcomes for children (Brumbach, Figueredo and Ellis 2009). Very little is known about how Indigenous youths negotiate relationships, define risk, conceptualise their sexuality and sexual decision-making, or how their views may be influenced by the culture and society in which they live (Senior 2003). Indigenous sexual and reproductive health has long been a priority with successive governments. Many interventions (Guy et al. 2012) have been designed to address this issue but, despite some success, particularly in the reduction of sexually transmitted diseases, young Indigenous women continue to bear a significant burden.

Over the years, I have come to appreciate that young Indigenous women, living within a society at least partially governed by customary law, may experience a disconnection from the larger world and its social and cultural norms. Young Indigenous women living in the community and town examined in this chapter have many issues with which to contend. Remote Aboriginal communities have been severely tested by substance 
misuse and social disruption, a consequence of violent displacement from traditional lands and the introduction of welfare, alcohol and other drugs. Under such circumstances, young Aboriginal women trying to negotiate the perils of early adolescence appear to have no clear pathways (MacDonald and Boulton 2011; Burbank, Senior and McMullen 2015).

\section{The Young Women}

As a group, the young Aboriginal women in both the community and the town are difficult to reach. The mid-teenage group who are the focus of my study are intermittent attenders of school and tend to only become visible in the evening when they 'walk around' with groups of friends, usually sisters and cousins (see Senior and Chenhall 2008). Although the behaviours in both the community and town are similar, the appearance of the young women is markedly different. The young women in the community affect a very discrete form of dress, with long skirts (often with shorts underneath) or baggy shorts and tee-shirts. Shoulders and chest are well covered and there is little evidence of hairstyling or make-up. Chenhall et al. (Chapter 2, this volume) argue that, in Ngukurr, a closely related community, attention to dress and make-up constitutes a form of imagined defiance for young women, whose elders and partners exhort them to not stand out. A young woman in a relationship was expected to be as inconspicuous as possible so as not to provoke the jealousy of their partners (Senior and Chenhall 2008). In contrast, the young women in the town wore extremely short and revealing denim shorts and paid attention to their hair and make-up, especially when they were out walking with their friends.

\section{Relationships and Sex}

Although achieving a relationship is frequently a driving force in young women's lives, they are often deeply ambivalent about the realities of being in a relationship, especially one that involves babies. Many young women in both the community and the town commented that they had to stay at home all day looking after the house and children and food. Some young women told me that if they did not have food on the table when their husband awoke, they could be 'in for a thrashing' (see also Senior and Chenhall 2012, 380). Going to the shop to buy food and taking 
their children to the clinic were their main outings. They would also visit family members and, if they had enough money, they might join in a card game. Young women with children said that, although unmarried girls could access the youth centre and its activities, young mothers of the same age were stuck at home with their children. Their days of 'walking around at night' (Senior and Chenhall 2008), and all the fun and danger that represented, were now over (McMullen 2015).

Although most of the young women I spoke with said they would prefer a steady relationship with a loving partner, they were aware that this was not always possible. When they looked around, they saw relationships marred by heavy drinking, drug use and family violence, and many sought a way around this problem. One of the few ways that independence could be achieved was via welfare. Having children on their own allowed them to collect benefits that provided some measure of financial independence. However, this strategy was not without risk, as they were only able to maintain this state of affairs by resisting any form of permanent alliance/ marriage with a male partner who may view their income, and indeed their life, as his own. Many women told me that they had endeavoured to keep their own money, but that they were not always successful (McMullen 2015).

Despite the risks, for some young women the 'single mother' life is a key aspiration as it is a means of achieving financial independence; therefore, some young women actively seek and form relationships that support this strategy (see also Chapter 2, this volume). A number of locals in both the community and the town told me that some young girls choose partners for their financial status and/or their ready access to alcohol and other drugs. Not being in a traditional relationship may also mean that young women are able to change partners or add additional partners if the relationship no longer meets their needs, especially in the areas of economic assistance or access to gifts or substances. Further, having casual partners may mean that young women are less likely to become victims of violence. For example, I once heard a young woman say that a woman with a few partners may find that young men fight among themselves for her favour instead of subjecting her to the forms of violence that can occur in more permanent relationships (McMullen 2015).

In order to attract partners, whether temporary or permanent, young women with few resources may rely on their powers of sexual attraction and go to great lengths to obtain appealing clothing, hair styles and 
jewellery, which is difficult due to their distance from large shops and the high price of such things in small, community shops. Although young women may hold the balance of power in deciding with whom to have sex, they may not have power in deciding how this encounter is managed and this is particularly the case when they try to negotiate condom use. It is well documented that men do not like to use condoms and will endeavour to persuade a woman by various means that a condom is not necessary (Mooney-Somers et al. 2012). Mooney-Somers et al. (2012) have noted that young disadvantaged Indigenous women are most at risk in this area of negotiation. The most obvious risks of unprotected sex are pregnancy and sexually transmitted infections. Although the risk of pregnancy may be managed by other methods such as Implanon (a skin implant that releases estrogen for a period of three years) ${ }^{1}$ or the pill, the risk of sexually transmitted infections remains the same. How do young women manage these risks?

The obvious answer is condom usage, but this can depend on a number of factors beyond those just mentioned. Access to condoms can be a problem in both the community and town and can largely depend on the local health clinic's policy. Rather than requiring people to come to the clinic to ask for condoms, health personnel may leave condoms out in a specific area for people to take. There remain significant barriers to young people actually carrying condoms. In Borroloola, I was told by young women that it was a 'shame job' for a woman to carry around condoms. Even if it were not a shame job, young women rarely carry around a hand or shoulder bag, so they would have to stow condoms in their bra if they carried one at all.

Senior and Chenhall (2008, 2012; Chenhall and Senior 2017) have described the imbalance of power between males and females in negotiating sexual encounters, with females reluctant to do anything (such as suggest safe sex) that could potentially anger their partner and encourage them to move to another more willing one. Similarly, the young women in my study said that it could be difficult to get partners to use condoms and that they feared partners would get angry and accuse the young woman of thinking that they might have a disease. They anticipated that this could result in physical violence, which they wished to avoid and so they did

1 Implanon is the most common form of birth control used in remote communities. The Implanon capsule is injected into the upper arm by a doctor or a nurse and can be left in for three years. It is available for women aged 16 years and over. 
not insist on condom usage. They also pointed out that, when a young woman is under the influence of alcohol or other substances, she may not even be able to think through the risks involved (McMullen 2015).

There is also the problem of unwelcome sex. Many young women complained to me that, although they did not want sex with a particular man, they might engage in it rather than risk violence (see Senior, Helmer and Chenhall 2017). Although they did not regard this as rape, they would not have had sex if they were not afraid of the potential for violence. Sexual activity under duress appeared to be a perennial problem. Parents were not always able to intervene on their daughters' behalf, even if they knew about the problem, for fear of repercussions from the young man's family. The young man's uncles, I was told, might come to the community with spears to defend his reputation (McMullen 2015).

From my observations and work in both the community and town, looking for a partner appears to follow the same course. At night, young women walk around or attend parties in an effort to find a partner. Once found, a prospective partner must be held onto and defended against the wiles of other young women and this involves sexual relations (Senior and Chenhall 2008; 2012; Burbank et al. 2015).

The use of alcohol and drugs is another part of the picture, and this is where my work differs from that of Senior and Chenhall, who worked in a dry (alcohol-free) community. Older women in the town told me that many young women were having sex when they were drunk and did not appear to care with whom they had it. This invariably causes problems when it comes to the identity of the father if a child is conceived. One young person told me that young men had been known to have sex with their 'sister/cousins' while drunk and were very concerned about the results of this act. Some girls also appeared to be attracted to the idea of receiving food, clothing or other items, which is hardly surprising given the poverty of their circumstances. I have been told by locals that casual liaisons may sometimes involve married Indigenous men or non-Indigenous men and, although some community members have tried to discourage this, people claim that it is now accepted practice (McMullen 2015). In the town, where permits are not required and where there are frequent opportunities for interactions with non-Indigenous men, young females considered that the transient population of contracted workers fulfilled several positive attributes as sexual partners. They were new and different, had access to alcohol and drugs, and were unlikely to require a permanent relationship. As I noted in my field observations in 2012: 
I observed groups of girls heading out of town just after dark. An informant finally told me that these young girls were heading out to the contractor's camp. She said that these young girls were going to the camp to party with the contractors and that it was the 'new and cool place to be'. Here young girls could get grog and gunja in return for sexual favours.

\section{Sex Education}

Local people say that Indigenous people do not talk about sexual health in the home as it is not considered appropriate and people express concern that this sort of discussion may lead to young women 'mucking around'. Local schools offer little sexual health information, which is only provided to secondary students. As school attendance among adolescent girls is very poor, many do not receive the information about sexual and reproductive health that other Australian youths receive (McMullen 2015).

Pregnancy and child-bearing are central issues in Indigenous life; however, according to my informants, some families do not educate their daughters about sexual activity and contraception and are accepting of a daughter who falls pregnant at a young age. While they may not approve of their daughter's sexual activity, may growl at the girl and view her behaviour as a 'shame job', they regard the pregnancy as a done deal and there does not appear to be any negative consequences for the young woman (see also Burbank 1988). An informant once told me that many young pregnant girls are frightened about going to the clinic to confirm a pregnancy and will ask their mothers to go with them. A common answer to this is: 'I wasn't standing next to you when you got pregnant was I?' Support, however, is usually forthcoming.

According to Northern Territory Government regulations, any young girl under the age of 16 who is having sex, especially with a man at least two years older than she is, must be reported to a government agency. This is a part of the Northern Territory National Emergency Response Act 2007 (Australian Government 2007), known as 'the Intervention'. Mandatory reporting causes clinic staff much concern, both because the benefits to the wellbeing of the young woman are not clear and because they dislike violating confidentiality. There has been considerable protest from health professionals and many will not consider mandatory reporting (McMullen 2015). 


\section{Pregnancy and Birth}

In my experiences as a nurse working in a clinic in Arnhem Land, young women did not come to the clinic for urine pregnancy tests as soon as a period had been missed. They would present at about three months for a confirmation of what they likely already knew. Many women did not present to the clinic at all and it was the eagle-eye of an Aboriginal health worker who would tell the clinic midwife that someone was probably pregnant. Testing and treatment regimens in remote clinics are much the same as in non-Indigenous society. The most common problem in early pregnancy for an Indigenous woman is anaemia, which is usually dealt with by supplying iron tablets and instituting monthly check-ups. Expectant mothers who have rheumatic heart disease are usually sent to Darwin for risk analysis, as are mothers with gestational diabetes. Most pregnancies, however, proceed normally, with check-ups becoming more frequent as the birth approaches (McMullen 2015).

As is noted in the literature, Indigenous women appear to get pregnant for the first time at a much younger age than in non-Indigenous society (Thompson, Zhang and Dempsey 2012). This is not to say that young Indigenous girls or women are necessarily more sexually active than their non-Indigenous counterparts, but that they do not have the same access to sex education, contraception and abortion as young non-Indigenous women. While I was working as a nurse in the Arnhem Land community, I found the lowest age of first pregnancies to be 16 years. More commonly, girls' first pregnancies occurred in their late teens and early 20s. In the town, I talked to girls as young as 12 who were pregnant and found, from the perspective of community members, that 14-16 years was not an uncommon age for first pregnancies. Many of these young girls were having a baby at the same time as their mother. Childbirth occasions fear in many of the young Indigenous women with whom I am familiar. Much of this fear involves the need for women to be removed from the community and from the supports of their families when their due date approaches (usually at 36 weeks).

Although all remote clinics are mandated to have a midwife on staff and antenatal equipment, clinics are not set up for complex medical emergencies. For this reason, women nearing the time of birth are flown out of the community to deliver in the nearest regional centre. For Arnhem Land, this is Gove, and for the MacArthur River area, it is Katherine. If the birth is expected to be difficult, women from both areas may be flown to Darwin. 
These arrangements appear to create a stressful environment for new Indigenous mothers. I observed that most young women do not want to be separated from their family members at this time. Yet, they are flown out of the community, often without an escort, such as their partner or mother, to undergo labour in an unfamiliar urban hospital environment. Family members who have the money may seek to visit the urban centre to be with the birthing mother, but this is not always possible. Indigenous women living in urban centres and non-Indigenous women, including those living in remote areas, usually have their family members with them during this time, but remote-living young Indigenous women and girls who have little experience of the non-Indigenous world are sent off to have their babies with strangers (McMullen 2015). As Kildea, Barclay and Tracy (2010) point out in their argument for birthing on country, this removal not only creates stress for the woman and her baby, but also contributes to continuing poor reproductive outcomes by limiting the ability for continuing care in the community for mother and child.

\section{Alcohol and Other Abused Substances}

One of the main differences between the community and town is the ready availability of alcohol. I am not claiming that young women in the community do not drink, only that alcohol is not so readily available. By contrast, its presence in the town is all pervasive and often has a detrimental effect on the behaviour of young people. One woman said that young people 'find each other when they are drunk' and that alcohol loosens normal cultural inhibitions. Many older women criticised younger ones, saying that they were only interested in a man as long as he had money and access to substances such as grog and ganja (cannabis). These older women observed that some of the young ones were not interested in marriage and babies at all but preferred to party with anyone who could provide them with alcohol and ganja. They said that some girls did not marry young but lived with their parents or other relatives and had children and liaisons with different men.

Although alcohol and other factors appeared to have eroded community norms, most young women sought a steady partner with whom to raise a family. In the town, a 'young girl', about 14 years old, was pointed out to me and I was told: 'Ahhh, she all married up now'. The speaker then pointed to a young man, around 16 years of age, walking nearby and said he 
was the young woman's partner. I asked what would happen now, and my interlocutor said that the young woman would move into the house of the young man's parents; they were now considered as married. I asked whether the young woman's parents were in agreement with the arrangement. The reply was: 'Yare, he right skin for her'. ${ }^{2}$ I asked if this was the way young people usually became 'married'. The reply was 'yes'-if the young people were of the right skin groups. This speaker said that young people who made a 'wrong way marriage' were not taken as seriously by older people and that support for the marriage, especially if the marriage was experiencing difficulties, was not always forthcoming (McMullen 2015).

\section{Discussion and Conclusion}

The life of young Indigenous women in both the community and the town is not easy. Their lives are characterised by very short periods of childhood and what Brumbach, Figueredo and Ellis (2009) describe as a 'fast life strategy'. It is unclear whether this strategy is an adaptive response to the harsh environments in which they grow up or a result of the very limited set of choices governing their lives (see Senior and Chenhall 2008, 2012).

From birth, this group of women face a set of circumstances unlike those of most non-Indigenous Australians. They are born into a society that was forced to abandon many of its laws and practices, but they are directed (often through fear of supernatural retribution [see Senior and Chenhall 2013]) to conform to those that remain. They also are encouraged to exist in the non-Indigenous world and to conform to many of its norms and practices, language and values. Historical forces have influenced the cultural and social norms of the community and town studied here (Baker 1999). The community was sheltered from the worst of the destructive influences of European contact under the Arnhem Land reserve (Cole 1979, 1985), but other nearby communities and towns have suffered greatly, the ready availability of alcohol and associated rates of violence further destroying Indigenous life ways. This exposure has led to poor outcomes in the sexual and reproductive health of young Indigenous women, as drinking may lead to early sexual initiation, resulting in

2 By this, the person meant that the two young people were in appropriate categories of kin to get married. In both the remote community and the town, society is divided into moieties and a fundamental rule is that one must marry someone from the opposite moity to oneself. Further divisions into semi moieties and skins refine the possible choices that individuals can make. 
early pregnancy, increased rates of sexually transmitted infections, poor parenting standards and an increased risk of falling victim to family violence or assault. How young women cope with these outcomes appears to largely depend on the support they receive from family, community members and service providers. Importantly, the decisions these young women make regarding sexual and reproductive health will affect the remainder of their lives and the lives of the next generation.

\section{References}

Australian Government. 2007. Northern Territory National Emergency Response Act 2007. Canberra: Department of Families, Housing, Community Services and Indigenous Affairs.

Baker, R. 1999. 'Land is Life': From Bush to Town, the Story of the Yanyuwa People. Sydney: Allen \& Unwin.

Brumbach, B., A. Figueredo and B. Ellis. 2009. 'Effects of Harsh and Unpredictable Environments in Adolescence on Development of Life History Strategies-A Longitudinal Test of an Evolutionary Model'. Human Nature 20: 25-51. doi.org/10.1007/s12110-009-9059-3.

Burbank, V. K. 1988. Aboriginal Adolescence-Maidenhood in an Australian Community. New Brunswick: Rutgers University Press.

Burbank, V., K. Senior and S. McMullen. 2015. 'Precocious Pregnancy, Sexual Conflict, and Early Childbearing in Remote Aboriginal Australia'. Anthropological Forum 25 (3): 243-61. doi.org/10.1080/00664677.2015. 1027657.

Chenhall, R. and K. Senior. 2017. 'Living the Social Determinants of Health: Assemblages in a Remote Aboriginal Community'. Medical Anthropology Quarterly 32 (2): 177-95.

Cole, K. 1979. The Aborigines of Arnhem Land. Adelaide: Rigby.

Cole, K. 1985. From Mission to Church: The CMS Mission to the Aborigines of Arnhem Land 1908-1985. Bendigo, Vic.: Keith Cole.

Guy, R., J. S. Ward, K. S. Smith, J. Su, R. L. Huang, A. Targey, S. Skov, A. Rumbold, A. Silver, B. Donovan and J. M. Kalder. 2012. 'The Impact of Sexually Transmissible Infection Programs in Remote Aboriginal Communities, a Systematic Review'. Sexual Health 9 (3): 205-12. doi.org/10.1071/SH11074. 
Kildea, S. V., L. M. Barclay and S. Tracy, S. 2010. "“Closing the Gap", How Maternity Services Can Contribute to Reducing Poor Maternal and Infant Health Outcomes for Aboriginal and Torres Strait Islander Women'. Rural and Remote Health 10 (3): 1-18.

Macdonald, G. and J. Boulton. 2011. 'Reconceptualising Mothers: Mothers and Infants in Crisis in the Kimberley, Western Australia'. In An Anthropology of Mothering, edited by M. Walks and N. McPherson, 133-48. Toronto: Demeter Press.

McMullen, S. 2015. 'Growing Up Fast'. PhD thesis, Charles Darwin University.

Mooney-Somers J., A. Olsen, W. Erick, R. Scott, A. Akee and L. Maher. 2012. 'Young Indigenous Australians' Sexually Transmitted Infection Prevention Practices: A Community-Based Participatory Research Project'. Journal of Community \& Applied Social Psychology 22 (6): 519-32. doi.org/10.1002/ casp. 1134 .

Senior, K. 2003. 'A Gudbala Laif? Health and Wellbeing in a Remote Aboriginal Community-What Are the Problems and Where Lies Responsibility?' $\mathrm{PhD}$ thesis, The Australian National University, Canberra.

Senior, K. and R. Chenhall. 2008. "Walkin' about at Night": The Background to Teenage Pregnancy in a Remote Aboriginal Community'. Journal of Youth Studies 11 (3): 269-81. doi.org/10.1080/13676260801946449.

Senior, K. and R. Chenhall. 2012. 'Boyfriends, Babies and Basketball: Present Lives and Future Aspirations of Young Women in a Remote Australian Aboriginal Community'. Journal of Youth Studies 15 (3): 369-88. doi.org/10.1080/13676 261.2012.663890.

Senior, K. and R. Chenhall, R. 2013. 'Health Beliefs and Behaviour, the Practicalities of "Looking After Yourself" in an Australian Aboriginal Community'. Medical Anthropology Quarterly 27 (2): 155-74. doi.org/10.1111/maq.12021.

Senior, K., J. Helmer and R. Chenhall. 2017. “'As Long as He’s Coming Home to Me”, Vulnerability, Jealousy and Violence in Young People's Relationships in Remote, Rural and Regional Australia'. Health Sociology Review 26 (2): 204-15. doi.org/10.1080/14461242.2016.1157697.

Stark, A. and A. Hope. 2007. 'Aboriginal Women's Stories of Sexually Transmissible Infection Transmission and Condom Use in Remote Central Australia'. Sexual Health 4 (4): 237-42. doi.org/10.1071/SH07009.

Thompson F., X. Zhang and K. Dempsey. 2012. Northern Territory Midwives' Collection. Mothers and Babies 2007. Darwin: Department of Health. 
This text is taken from Indigenous Australian Youth Futures: Living the Social Determinants of Health, edited by Kate Senior, Richard Chenhall and Victoria Burbank, published 2021 by ANU Press, The Australian National University, Canberra, Australia.

doi.org/10.22459/IAYF.2021.07 